\title{
A novel G-protein-coupled receptor-signaling platform and its targeted translation in human disease
}

\author{
Samar Abdulkhalek' \\ Michael Hrynyk² \\ Myron R Szewczuk' \\ 'Departments of Biomedical and \\ Molecular Sciences, ${ }^{2} \mathrm{C}$ hemical \\ Engineering, Queen's University, \\ Kingston, ON, Canada
}

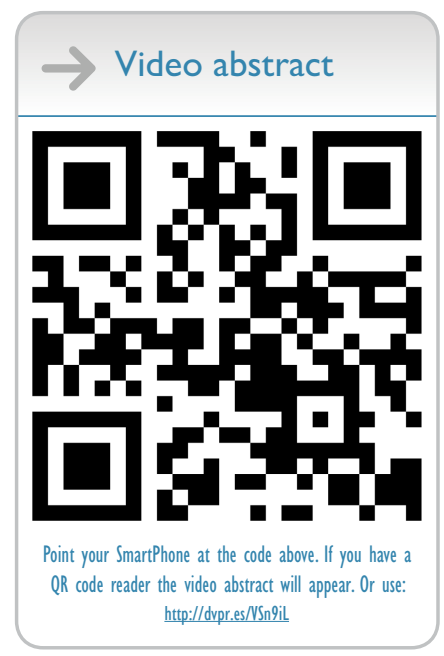

Correspondence: Myron R Szewczuk Department of Biomedical and Molecular Sciences, Queen's University, Kingston, ON K7L 3N6, Canada

Tel + I 6135332457

Fax +I 6I3 5336796

Email szewczuk@queensu.ca
This article was published in the following Dove Press journal:

Research and Reports in Biochemistry

4 January 2013

Number of times this article has been viewed

\begin{abstract}
Molecular-targeted G-protein-coupled receptor (GPCR) signaling in human disease has become an important area of scientific and medical research. The interactions between GPCRs with their large number of different G-protein subunits and the large number of glycosylated receptors involved in human diseases are quite diverse. One GPCR is capable of interacting with more than one $G$ protein to initiate multifunctional signaling. However, the activation of a number of GPCRs does not always lead to a direct effect alone on a particular signaling pathway, but rather to an amplification of the response produced by a separate circumstantial signal within the cell. This cross talk among different GPCR transduction signals is a focus of intense research. In this review, evidence exposing the invisible link connecting ligand-binding and receptor activation to a novel GPCR-signaling platform will be reviewed in relation to human disease.
\end{abstract}

Keywords: G-protein-coupled receptors, toll-like receptors, receptor tyrosine kinase, glycosylation, Neu1 sialidase, matrix metalloproteinase 9

\section{Introduction}

G-protein-coupled receptors (GPCRs) comprise the largest family of cell-surface signal-transduction molecules in mammalian cells. A vast array of stimuli is capable of eliciting conformational changes in these receptors, resulting in the activation of intracellular heterotrimeric G proteins. ${ }^{1}$ They are activated by many ligands, both internal within the body, such as hormones and neurotransmitters, and external light, odorants, and others. GPCRs undergo conformational changes upon ligand interaction, which results in the intermediate coupling and activation of guanine triphosphate (GTP)-binding G proteins (guanine nucleotide regulatory proteins, which are composed of $\alpha-, \beta$ - and $\gamma$-subunits), leading to the exchange of GDP for GTP on the Go subunit. This interactive process(es) of G proteins results in the dissociation of the GPCR receptor from the G proteins as well as the $G \alpha_{\text {ATP }}$ subunit from the $G \beta \gamma$ subunit. Both subunits are able to interact with various effector enzymes, leading to complex G-protein-mediated signaling pathway(s). ${ }^{1-8}$

These heterotrimeric $\mathrm{G}$ proteins are classically categorized by their $\alpha$ subunits, and can be grouped into four major families: $\mathrm{G}_{\mathrm{s}}, \mathrm{G}_{\mathrm{i} / \mathrm{o}}, \mathrm{G}_{\mathrm{q} / 11}$, and $\mathrm{G}_{12 / 13}{ }^{9}$ However, alternate pathways of GPCR-mediated signaling that are independent of G-protein interaction and/or activation of secondary effector molecules have been increasingly reported. These alternate GPCR-signaling responses are the result of cross talk between various intracellular signaling networks. ${ }^{1}$ For a number of these GPCRs 
to date, their ligands are still unknown, and their receptors are classified as GPCR orphans. ${ }^{10}$

Studies have shown that glycosylation of secreted and cell membrane-bound receptors is an important requirement for their transport and function. For example, partial glycosylation is an important requirement for at least the processing and/or ligand-binding activity of insulin receptor, ${ }^{11}$ epidermal growth factor receptor, ${ }^{12,13}$ nicotinic acetylcholine receptor, ${ }^{14}$ and members of the G-protein-coupled class of receptors, such as the vasoactive intestinal peptide receptor, ${ }^{14}$ somatostatin receptor, ${ }^{15}$ and $\beta$-adrenergic receptor. ${ }^{16,17}$ For nerve growth factor (NGF) tropomyosin receptor kinase A (TrkA) receptors, glycosylation is required to localize the receptor to the cell surface, where glycosylation is suggested to prevent receptor autophosphorylation. ${ }^{18}$ In addition, the treatment of TrkA-expressing cells by exogenous Trypanosoma cruzi trans-sialidase or $\alpha 2,3$-neuraminidase (Streptococcus pneumoniae) leads to TrkA activation sufficient to promote cell differentiation (neurite outgrowth) ${ }^{19}$ and neuroprotection against oxidative stress, serum/glucose deprivation, and hypoxia-induced neurite retraction. ${ }^{20}$ Based on these latter results, it was proposed that a specific $\alpha-2,3$-sialyl residue linked to $\beta$-galactosyl sugars of TrkA are rapidly targeted and hydrolyzed by a membrane sialidase(s) induced by NGF binding to $\operatorname{TrkA} .^{21}$

It is well known that glycoproteins and glycolipids expressed at the cell surface of eukaryotic cells can be modified to varying degrees by the addition of sialic acids ( $N$-acetylneuraminic acid or other $N$ - and $O$-substituted neuraminic acids). ${ }^{22}$ Sialic acid residues in specific linkages are known to control the chemical and biological properties of cell surfaces ${ }^{23}$ and the exposure of epitopes. ${ }^{24}$ Sialic acids play important roles as molecular determinants of specific biological processes such as cell-cell interactions, ${ }^{25-28} \mathrm{~T}$ - and B-cell activation, hematopoietic cell differentiation, ${ }^{22}$ tumorigenicity, and metastatic behavior of malignant cells ${ }^{29}$ and the control of Fas-mediated apoptosis. ${ }^{22}$ Although there is extensive literature on the role of sialic acid in protein structure (see reviews ${ }^{30-32}$ ), there are very few examples of a role for sugars in signal transduction. One is the addition of a single sugar to the Notch receptor, which becomes substituted and eventually obtains sialic acids on the terminus of the chain. Notch is a large cell-surface receptor known to be an essential player in a wide variety of developmental cascades. This single $O$-linked carbohydrate modification is essential for Notch signaling. ${ }^{33}$ The other examples are the role of glycosylation in TrkA activation by $\mathrm{NGF}^{21}$ and in Toll-like receptor (TLR-2, -3, and -4) activation by their respective TLR ligands. ${ }^{34,35}$

\section{Novel GPCR-signaling platform for tyrosine kinase receptors}

For TrkA receptors, we have reported that there is a mammalian neuraminidase-1 (Neu1 sialidase) and matrix metalloproteinase-9 (MMP-9) cross talk on the cell surface, which was an essential requirement for regulating NGF activation of TrkA receptors. ${ }^{36}$ It discloses a novel receptor-signaling paradigm involving NGF-induced GPCR-signaling process via $G \alpha_{i}$ proteins and MMP-9 activation in inducing Neu1 sialidase, all of which form a tripartite complex with TrkA at the ectodomain on the cell surface (Figure 1). MMP-9, or gelatinase B, is one of the largest and most complex member of the MMP family of at least 28 members. ${ }^{37}$ MMP-9 can bind to gelatin, collagens type I, IV, and V, and other substrates. ${ }^{38,39}$ It is the elastin-degrading activity of MMP- $9^{40,41}$ that fits well within this novel signaling paradigm of TrkA activation. This process involves the elastin-binding protein (EBP) as part of the molecular multienzymatic complex that contains $\beta$-galactosidase/Neu1 and protective protein cathepsin A. Direct removal of EBP from the complex by activated MMP-9 is proposed to activate Neu1. Alternatively, binding of elastin fragments to EBP may induce activation of Neu1 by EBP dissociation, subsequently allowing activated Neu1 to desialylate the $\alpha-2,3$ sialyl residues of TrkA and to facilitate receptor association and activation. ${ }^{36}$

It is known that Neul sialidase is associated with a serine carboxypeptidase (protective protein cathepsin A), $\beta$-galactosidase and $N$-acetylgalactosamine-6-sulfate sulfatase in the lysosome. ${ }^{42}$ Cathepsin $\mathrm{A}$ is required for normal Neu1 enzymatic activity ${ }^{43}$ and is sorted to the plasma membrane of differentiating monocytes similar to Neu1. ${ }^{42}$ Cell-surface Neu1/cathepsin A can also associate with EBP, forming the elastin receptor complex, where the catalytic activity of Neu1 facilitates elastic fiber assembly ${ }^{44}$ and signal transduction. ${ }^{45}$ Neul can be detected not only within the lysosome matrix but also in the plasma membrane under conditions of cell stimulation. ${ }^{46}$ In another study, Neu1 was found to negatively regulate lysosomal exocytosis in hematopoietic cells where it processes the sialic acids on the lysosomalassociated membrane protein $1 .{ }^{47}$ On the cell surface, we have reported an unprecedented role for Neu1. ${ }^{36}$ It forms a complex with TrkA receptors, as depicted in Figure 1, but also forms a complex with TLR2, -3 , and -4 receptors on the cell surface, which has not been previously observed. ${ }^{34,35}$ 


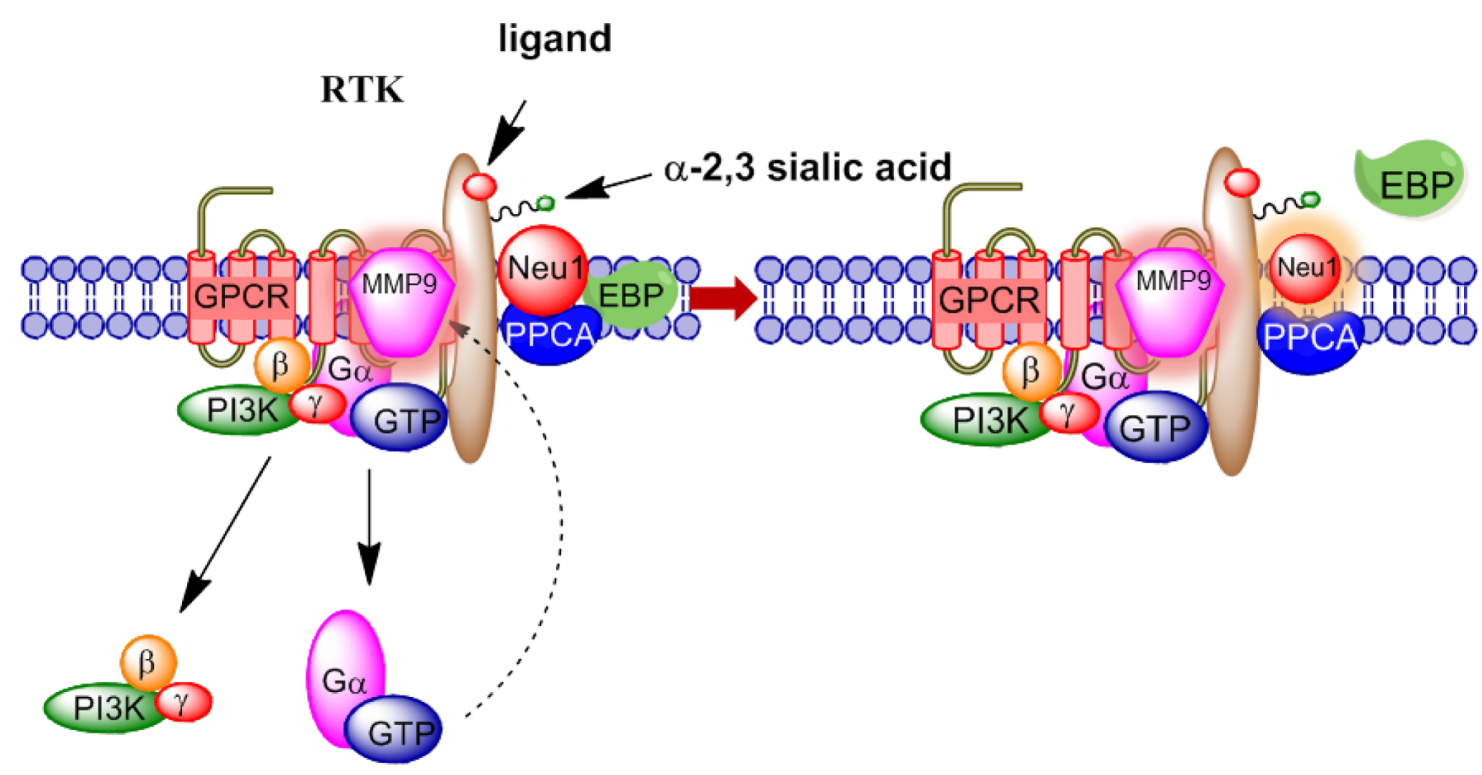

Figure I A novel molecular organizational G-protein-coupled receptor (GPCR)-signaling platform potentiates neuraminidase-I (Neul) and matrix metalloproteinase-9 (MMP-9) cross talk on the cell surface that is essential for the activation of receptor tyrosine kinases (RTKs).

Notes: The nerve growth factor (NGF) ligand-binding tropomyosin receptor kinase A (TrkA) receptor induces the GPCR-signaling process via Goi-proteins and MMP-9 activation in inducing Neul sialidase. ${ }^{36}$ Activated MMP-9 is proposed to remove the elastin-binding protein (EBP) as part of the molecular multienzymatic complex that contains $\beta$-galactosidase/Neul and protective protein cathepsin A (PPCA). Activated Neul hydrolyzes $\alpha-2,3$ sialyl residues of TrkA to facilitate receptor association and activation. Abbreviations: PI3K, phosphatidylinositol 3-kinase; GTP, guanine triphosphate.

There are three other mammalian sialidases that have been classified according to their subcellular localization. ${ }^{48}$ They are cytosolic Neu2, plasma membrane-bound Neu3, and Neu4. The cytosolic Neu2 sialidase normally shows lower expression levels among the mammalian sialidases, except for high Neu2 levels in skeletal muscle, ${ }^{49,50}$ the liver, ${ }^{51}$ and the thymus, ${ }^{52}$ and low levels in the brain. ${ }^{53}$ Membrane Neu3 sialidase appears to specifically hydrolyze monosialotetrahexosylgangliosides, ${ }^{54-56}$ and is referred to as plasma membrane ganglioside sialidase. ${ }^{57,58}$ A new Neu4 sialidase was cloned from murine brain and has similarities to Neu3. ${ }^{59}$ There is evidence for a human Neu4 sialidase localized to the mitochondrial ${ }^{60}$ and the lysosomal lumen. ${ }^{61}$ However, there is a paucity of information for a function role of Neu4 sialidase. We have recently reported that thymoquinone, an extract from black seed oil, induces Neu4 activation. ${ }^{62,63}$ In Figure 2, activated Neu 4 in alliance with MMP-9 and GPCR signaling via pertussis toxin-sensitive $\mathrm{G} \alpha_{\mathrm{i}}$ proteins was found to play an important role in regulating TLRs. ${ }^{63}$

Stomatos and colleagues have shown that Neu1 on the cell surface is tightly associated with a subunit of cathepsin A, and the resulting complex influences cell-surface sialic acid in activated cells in the production of interferon (IFN)- $\gamma \cdot{ }^{64}$ At the genetic level, Neu1-deficient mice produced markedly less immunoglobulin (Ig) $\mathrm{E}$ and $\mathrm{IgG}_{1}$ antibodies following immunization with protein antigens, which may be the result of their failure to make interleukin (IL)-4 cytokine. ${ }^{65}$ Using similar Neu1-deficient mice, we have found that serum proinflammatory cytokines are induced in wild-type (WT) and Neu1-deficient mice in response to lipopolysaccharide (LPS) after 5 hours of treatment when compared to basal serum levels. ${ }^{35}$ However, the Neu1deficient mice in response to LPS produced a significant reduction in complement $\mathrm{C} 5$ component fragment (C5a), granulocyte colony-stimulating factor, IL-1 receptor antagonist, IL-6, cytokine-induced neutrophil chemoattractant, and macrophage inflammatory protein- 2 cytokines compared to the WT mice. Using an IL-6 enzyme-linked immunosorbent assay, serum IL-6 was significantly reduced in LPS-treated Neu1-deficient mice compared to the WT cohort. In addition, in vitro treatment of human monocytic THP-1 with oseltamivir phosphate (Tamiflu) dose-dependently inhibited IL- 6 and tumor necrosis factor (TNF)- $\alpha$ production in response to LPS. ${ }^{35}$ Oseltamivir phosphate also significantly inhibited the production of nitric oxide (NO) in DC2.4 dendritic cells in response to LPS or killed Mycobacterium butyricum stimulation. These results are consistent with other reports indicating that oseltamivir reduces a synergy between influenza and IFN- $\gamma$ in NO synthesis in RAW 264.7 macrophages dose-dependently. ${ }^{66}$ It is noteworthy that Tamiflu is the ethyl ester prodrug of the anti-influenza drug oseltamivir carboxylate, which is converted to this biologically active form in vivo. ${ }^{67}$ Since Tamiflu is known to be ineffective in vitro because its antiviral activity is achieved 


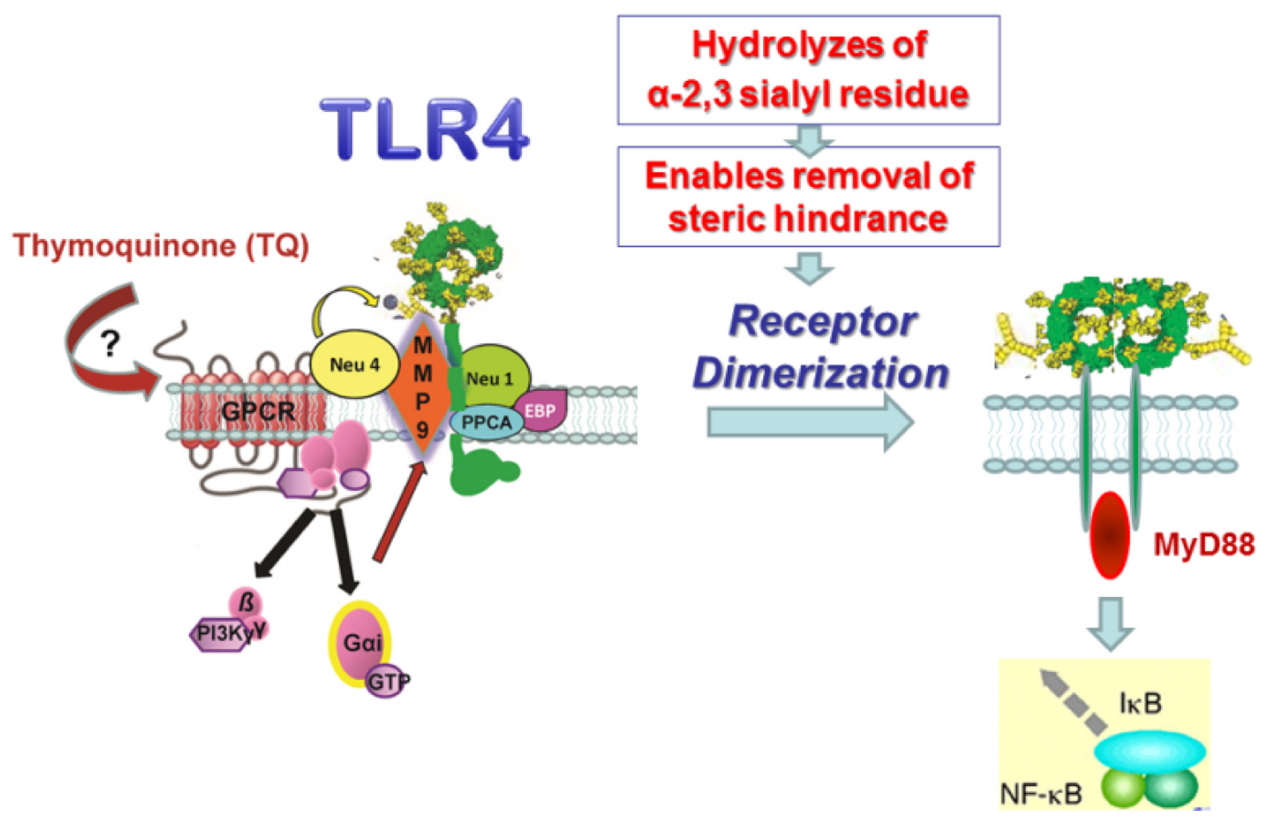

Figure 2 Thymoquinone (TQ) derived from the nutraceutical black cumin oil has been reported to be a novel agonist of Neu4 sialidase activity in live cells. ${ }^{62,63}$

Notes: The activation of neuraminidase-4 (Neu4) sialidase on the cell surface by TQ was found to involve G-protein-coupled receptor (GPCR) signaling via membrane targeting of $G_{\alpha i}$ subunit proteins and matrix metalloproteinase-9 (MMP-9) activation. Contrary to other reports, TQ had no anti-inflammatory effects in vitro. Here, MyD88/ TLR4 complex formation and subsequent NF- $\kappa B$ activation are induced by the Neu4 activity associated with TQ-stimulated live primary bone marrow macrophage cells from wild-type and Neul-deficient mice. The findings establish an unprecedented signaling paradigm for TQ-induced Neu4 sialidase activity. It signifies that MMP-9 forms an important molecular signaling platform in complex with TLR4 receptors at the ectodomain and acts as the intermediate link for TQ-induced Neu4 sialidase. Activated Neu4 generates a functional receptor with subsequent NFKB activation and pro-inflammatory cytokine production in vivo.

Abbreviations: TLR4, Toll-like receptor 4; Neu, neuraminidase; PPCA, protective protein cathepsin A; GTP, guanine triphosphate; EBP, elastin-binding protein; NFKB, nuclear factor kappa light-chain enhancer of activated B cells.

by the hydrolytic metabolite oseltamivir carboxylate form, ${ }^{68}$ we have actually observed the opposite effect in our livecell assay system..$^{35,69}$ To further elucidate the inhibitory capacity of Tamiflu and its hydrolytic metabolite oseltamivir carboxylate, the $50 \%$ inhibitory concentration $\left(\mathrm{IC}_{50}\right)$ of each compound was determined by plotting the decrease in sialidase activity against the $\log$ of the agent concentration. Tamiflu was found to have an $\mathrm{IC}_{50}$ of $1.175 \mu \mathrm{M}$ compared to an $\mathrm{IC}_{50}$ of $1015 \mu \mathrm{M}$ for oseltamivir carboxylate. ${ }^{35}$ These data clearly illustrated that Tamiflu is 1000 -fold more potent than its hydrolytic metabolite in inhibiting the sialidase activity associated with TLR ligand-treated live BMC-2 macrophage cells. Together, these results clearly indicated that Tamiflu is a potent inhibitor of the sialidase associated with TLR ligand-treated live macrophage cells. ${ }^{35}$

To further confirm Neu1 involvement in LPS-induced NO production and proinflammatory cytokines, primary bone marrow (BM) macrophage cells from Neu1-deficient mice were found to exhibit a significant reduction in endotoxin LPS-induced NO production in comparison to a WT cohort. ${ }^{35}$ Primary BM macrophage cells derived from CathA KI mice (normal Neu1 and inactive cathepsin A) or Neu4 knockout mice exhibited LPS-induced NO production comparable to the WT cohort. Here, it was proposed that TLR ligand-induced proinflammatory IL-6, TNF- $\alpha$ cytokines, and NO production are partially dependent on Neu1 sialidase activity. ${ }^{35}$

\section{A novel GPCR-signaling platform for Toll-like receptors}

Evidence for the interaction between TLRs and GPCRs came initially from the effect of TLRs on GPCR activity. Activation of TLRs has been shown to regulate GPCR responsiveness by modulating the expression of GPCR kinases (GRKs), arrestins (ARRs), and regulators of G-protein-signaling (RGS) proteins. ${ }^{70,71}$ GRKs phosphorylate and ARRs bind to GPCRs to inhibit G-protein-dependent signaling. Various RGS proteins that act specifically on different $G \alpha$ subunits and thus stimulate specific pathways are induced by specific TLRs. ${ }^{70}$ For example, the RGS proteins are known to control the rate of GTP hydrolysis on the G $\alpha$ subunit of heterotrimeric G proteins. Together with GRKs and ARRs, they regulate the duration of signaling downstream of GPCRs. Indeed, the RGS family of proteins, comprising 30 members, is diverse, ranging in size from $17 \mathrm{kDa}$ to $160 \mathrm{kDa}$ and displaying widely variable and regulated expression patterns. ${ }^{72}$ Most RGS proteins have GTPase 
activity specific for the $G \alpha_{i}$ and $G \alpha_{q}$ subfamilies of the $\alpha$-subunits. Some RGS proteins can also function essentially as effector antagonists through competitive inhibition of effector-G $\alpha$-protein interactions. According to Lattin et al, the mRNA levels for $R G S 1,-2,-10,-18$, and -19 are highly expressed in macrophage cells or are strongly upregulated by the TLR4 receptor ligand LPS. ${ }^{70}$ It is unclear whether any of the RGS family of proteins form a complex with TLR receptors. However, there is evidence to indicate that RGS19 and GIPC (Go-interacting protein [GAIP] interacts specifically with the PDZ-containing protein, GAIP-interacting protein, C-terminus) heterodimer forms a complex with insulin growth factor receptor 1 (IGFR-1) to consolidate IGF-1 signaling to the mitogen-activated protein kinase (MAPK) activation. ${ }^{73}$ The RGS19/GAIC heterodimer has been shown to form a complex with the NGF receptor TrkA. ${ }^{74}$ It remains unclear how this complex affects signaling via these receptors.

Other studies have demonstrated that (1) proteinaseactivated receptor $2\left(\mathrm{PAR}_{2}\right)$ GPCR and TLR4 were physically associated, and coexpression of TLR4 and $\mathrm{PAR}_{2}$ enhanced nuclear factor kappa light-chain enhancer of activated $\mathrm{B}$ cells (NF-אB) signaling, ${ }^{75}$ and (2) the TLR4-associated CD14 protein coimmunoprecipitated with G-protein subunits, ${ }^{76}$ and CD14 associated with TLR4 in lipid membrane rafts. ${ }^{77}$ The physical association of TLRs with the GPCRs provides firstly the mechanism by which GPCRs can be activated upon TLRligand binding. The physical GPCR-TLR association could also facilitate the transmission of the signal from the GPCR to the Neu1/TLR complex and consequently to the TLRs. ${ }^{78}$ Taken together, these studies strongly suggest that TLRs and GPCRs are found associated, physically and functionally, in cellular functioning. GPCR signaling appears to influence TLR signaling early on, perhaps at the receptor level. In macrophages and dendritic cells, for example, GPCRs regulate diverse cell functions, including cell-cell interactions, survival, chemotaxis, and activation, involving cross talk between GPCR- and TLR-signaling pathways. ${ }^{70,79}$

The involvement of heterotrimeric G $\alpha$ proteins in ligandmediated TLR function has been reported. Solomon et al ${ }^{76}$ have demonstrated that CD14 (an integral component of the Gram-negative bacterial LPS-receptor complex, along with TLR4 and MD2) was associated with $\mathrm{G}_{\mathrm{i}}$ (inhibitory class) and $\mathrm{G}_{\mathrm{o}}$ (olfactory class) $\alpha$ subunits of $\mathrm{G}$ proteins. The report also indicated that heterotrimeric $G$ proteins have a specific regulatory function in CD14-mediated LPS-induced MAPK activation and cytokine production in normal human monocytes. When human monocyte THP-1 cells were pretreated with pertussis toxin which specifically inhibits $G \alpha_{i}$-receptor coupling, there was a significant decrease in LPS-induced activation of c-Jun N-terminal kinase and p38 kinase, and the production of TNF- $\alpha .{ }^{80}$ In addition, Fan et al ${ }^{81}$ have shown that $G \alpha_{i}$ protein differentially regulates LPSmediated signaling through TLR4, and Gram-positive Staphylococcus aureus-mediated signaling through TLR2. Using the knockout mouse models $\mathrm{G \alpha}_{\mathrm{i} 2}{ }^{-/-}$and $\mathrm{G \alpha}_{\mathrm{i} 1 / 3}{ }^{-/-}$, the study showed significantly decreased TLR ligand-mediated TNF- $\alpha$ and IL-10 production in peritoneal macrophages of the knockout mice compared to WT mice. Surprisingly, in splenocytes from the same knockouts, significant increases in TNF- $\alpha$ and IFN- $\gamma$ production in response to TLR ligands were detected. These data suggest a regulatory role for $\mathrm{G} \alpha$ proteins in TLR signaling that is potentially dependent on the cellular phenotype ${ }^{81}$ In the murine RAW 264.7 macrophage cell line, and primary murine macrophages, G-protein dysregulation by wasp venom-derived peptide mastoparan caused a significant inhibition in LPS-induced TLR4- but not TLR2-mediated gene expression. ${ }^{82}$ It is well known that mastoparan directly activates $\mathrm{G}_{\mathrm{i}}$ (inhibitory class) and $\mathrm{G}_{\mathrm{o}}$ (olfactory class) $\alpha$ subunits of $\mathrm{G}$ proteins. However, the mastoparan-induced biological responses are not always explained by this mechanism. For instance, mastoparan was shown to change the localization of $G \alpha_{q / 11}$ and $G \beta$ together with cholesterol from lipid rafts to nonraft fractions or to the cytosol. ${ }^{83}$ These changes were inhibited by ganglioside mixtures, suggesting that mastoparan interacts with gangliosides in lipid rafts. In fact, ganglioside mixtures and neuraminidase, but not sialic acid, attenuated the inhibitory effect of mastoparan on phosphoinositide hydrolysis. These results suggest that mastoparan initially binds to gangliosides in lipid rafts and then inhibits phosphoinositide hydrolysis by changing the localization of $\mathrm{G} \alpha_{q^{\prime 11}}$ and $\mathrm{G} \beta$ in lipid rafts.

The mammalian TLRs are sensor receptors that recognize pathogen-associated molecular patterns. Not only are TLRs important sensors of microbial infections for innate immune cells, they also play important roles in the pathophysiology of inflammatory and autoimmune diseases. The intensity and duration of TLR responses with these diseases must be tightly controlled. Although the signaling pathways of TLR sensors are well characterized, the parameters controlling interactions between TLRs and their ligands have remained poorly defined until now.

For the majority of TLR receptors, dimerization is a prerequisite to facilitate myeloid differentiation primary response gene-88 (MyD88)-TLR complex formation and subsequent cellular signaling to activate NF- $\kappa B$. We 
previously reported that Neu1 is an important intermediate in the initial process of TLR ligand-induced receptor activation and subsequent cell function. ${ }^{34,35}$ The data indicated an initial rapid activation of Neul activity that was induced by ligand binding to the receptor. Central to this process is that only Neu1 forms a complex with TLR2, -3 or -4 receptors in naïve TLR-expressing cells or primary macrophage cells. However, an unprecedented membrane-signaling paradigm initiated by TLR ligands binding to TLR receptors was recently uncovered. ${ }^{84}$ The results indicated that the interaction of TLR ligands with their receptors initiates the potentiation of GPCR-signaling via membrane $G \alpha_{i}$ subunit proteins and MMP-9 activation to induce Neu1 activity. Neu1 together with GPCR-signaling $G \alpha_{i}$ subunit proteins and MMP-9 form a complex with TLRs on the cell surface of TLR-expressing cells. This tripartite alliance makes Neul readily available to be induced by TLR ligands binding to their receptors. It is well known that agonist-bound GPCRs have been shown to activate numerous MMPs, ${ }^{85}$ including MMP-3, ${ }^{86} \mathrm{MMP}-2$, and $-9,{ }^{87,88}$ as well as members of the A disintegrin and metalloproteinase (ADAM) family of metalloproteases: ADAM10, ADAM15, and ADAM17. ${ }^{89,90}$ This membrane-signaling paradigm suggests a Neu 1 and MMP-9 cross talk in alliance with GPCR signaling through $\mathrm{G} \alpha_{i}$ proteins and TLRs on the cell surface to mediate receptor activation. ${ }^{84}$ Our other reports ${ }^{21,34,35,63,69}$ support a receptor glycosylation model in corroborating the importance of activated Neu1 hydrolysis of sialyl $\alpha$-2,3-linked $\beta$-galactosyl residues of TLR in the initial stages of ligand-induced receptor activation. This desialylation process is proposed to remove steric hindrance to TLR dimerization, MyD88/TLR complex recruitment, NF- $\kappa \mathrm{B}$ activation, and proinflammatory cytokine response. ${ }^{34,35}$

Conversely, it is well known that GPCR agonists can induce transactivation of TLR receptors independently of TLR ligands, ${ }^{70,79}$ but the mechanism(s) behind GPCR agonistinduced transactivation of TLRs in the absence of TLR ligands is unknown. We have recently reported a molecular organizational GPCR-signaling platform that potentiates Neu1 and MMP-9 cross talk at the ectodomain of TLRs on the cell surface. ${ }^{78}$ This GPCR-signaling platform is proposed to be the cellular signaling mechanism for the transactivation of TLR receptors by GPCR ligands. It also predicts that TLRs are in alliance with a functional GPCR-signaling complex. The data show that GPCR agonists such as bombesin, lysophosphatidic acid (LPA), cholesterol, angiotensin-1 and -2, and bradykinin binding to their respective GPCR receptors can induce Neu1 activity within 1 minute, and that this activity is blocked by Go $\alpha_{i}$-sensitive pertussis toxin, neuraminidase inhibitor Tamiflu, broad-range MMP inhibitors galardin and piperazine, antiNeu1 and anti-MMP9 antibodies, and siRNA knockdown of MMP-9. The rapidity of the GPCR agonist-induced Neu1 activity suggests that glycosylated receptors like TLRs form a functional GPCR-signaling complex. In support of this hypothesis, the bombesin-related neuromedin-B receptor was found to form a complex tethered to TLR4 receptors on the cell surface in BMA (murine bone marrow macrophages immortalized with a retrovirus carrying oncogenes myc and $r a f$ ) macrophage cells. These data are consistent with reports describing cross talk between GPCR- and TLR-signaling pathways. $^{70,79}$ In addition, we have shown that other GPCR-specific agonists binding to their respective receptors induce sialidase activity in live macrophage cells. For example, LPA is a lysophospholipid whose functions are mediated by at least four GPCRs. These receptors couple to multiple $\mathrm{G}$ proteins, particularly $\mathrm{G}_{12 / 13}, \mathrm{G}_{\mathrm{i}}$, and $\mathrm{G}_{\mathrm{q}}$, and possibly $\mathrm{G}_{\mathrm{s}}$. Cholesterol has been reported to have a modulatory role in the function of a number of GPCRs. ${ }^{91}$ According to Paila and Chattopadhyay, ${ }^{91}$ membrane cholesterol could influence the structure and function of GPCRs (1) through a direct/specific interaction with GPCRs, (2) through an indirect way by altering membrane physical properties in which the receptor is embedded, or (3) due to a combination of both. Indeed, cholesterol-binding sites were shown to have inherent characteristic features of serotonin (1A) receptor which is a GPCR that is coupled to $\mathrm{G}_{\mathrm{i}} / \mathrm{G}_{\mathrm{o}}$ and mediates inhibitory neurotransmission. For the angiotensins, they mediate their actions via several specific $\mathrm{AT}_{1}, \mathrm{AT}_{2}$, and MAS receptors. The angiotensin receptor is activated by the vasoconstricting peptide $\mathrm{AT}_{2}$. The activated receptor in turn couples to $\mathrm{G}_{\mathrm{q} / 11}$ and thus activates phospholipase $\mathrm{C}$ and increases the cytosolic $\mathrm{Ca}^{2+}$ concentrations. Although $\mathrm{AT}_{1}$ has no biological effects, it was found to induce sialidase activity in our live-cell assay, which may provide an uncharacterized activity for this compound. ${ }^{78}$ For bombesin, all the receptor subtypes identified to date couple via $\mathrm{G}_{\mathrm{q} / 11}$ to the phospholipase $\mathrm{C}$-signaling pathway. For thrombin, we did not observe any sialidase activity when the cells were treated with it. The thrombin receptor is known to activate phosphoinositide metabolism via a pertussis toxininsensitive $\mathrm{G}$ protein. It also inhibits adenylyl cyclase via a pertussis toxin-sensitive $G$ protein. There are three known thrombin protease-activated receptors - termed $\mathrm{PAR}_{1}, \mathrm{PAR}_{3}$ and $\mathrm{PAR}_{4}$ - but their method of activation is known to be unique. Thrombin is a serine protease that binds to and cleaves the extracellular N-terminal domain of the receptor. A tethered ligand corresponding to the new N-terminus, SFLLRN, is unmasked, and it binds to the second extracellular loop of the 
receptor, thus activating the receptor. Bradykinin, on the other hand, binds to the ubiquitous and constitutively expressed $\mathrm{B}_{2}$ receptors which are members of the rhodopsin family of G-protein-coupled receptors. Through $\mathrm{G}_{\mathrm{q}}$-mediated signaling, $\mathrm{B}_{2}$ receptors stimulate phospholipase $\mathrm{C}$ to increase phosphoinositide hydrolysis and intracellular free $\mathrm{Ca}^{2+} . \mathrm{B}_{2}$ signaling through $\mathrm{G} \alpha_{i}$ also inhibits adenylate cyclase to stimulate the MAPK pathway. ${ }^{92}$ Collectively, the above GPCR agonists that induce Neu1 sialidase activity commonly use the $\mathrm{G}_{12 / 13}, \mathrm{G} \alpha_{\mathrm{i}}, \mathrm{G}_{\mathrm{q}}$ and $\mathrm{G}_{\mathrm{q} / 11}$ signaling proteins. ${ }^{78}$

Others have shown that sphingosine-1 phosphate (S1P) and $\mathrm{S}_{1} \mathrm{P}_{3}$ expressions are induced by LPS in human gingival epithelial cells (HGEC), and that these elevated expressions enhanced the influence of S1P in its cooperation with TLR4 to increase cytokine production. ${ }^{93}$ The relationship between GPCR signaling and TLR has also been shown for (1) CC chemokine ligand 2 synergizing with the nonchemokine G-protein-coupled receptor ligand $N$-formylmethionyl leucyl-phenylalanine in monocyte chemotaxis, ${ }^{94}(2)$ complement $\mathrm{C} 1 \mathrm{q}$ expression in macrophages requiring beta-arrestin 2 where beta-arrestins (ARRB1 and ARRB2) regulate GPCR-dependent and independent signaling pathways, ${ }^{95}$ (3) leukotriene B4 receptor BTL1 by reducing suppressor of cytokine signaling proteins 1 inhibition of MyD88 expression in mouse macrophages, ${ }^{96}$ and (4) GPCR-derived cyclic adenosine monophosphate signaling in influencing TLR responses in primary macrophages through peptide disruptors of A-kinase anchoring protein 10 involving prostaglandin $\mathrm{E}_{2} \cdot{ }^{97}$ Using MyD88 homodimerization inhibitor peptide, we have reported that GPCR bombesin activation of NF- $\kappa \mathrm{B}$ in macrophage cells is initially mediated via a novel molecular GPCR organizational signaling platform in concert

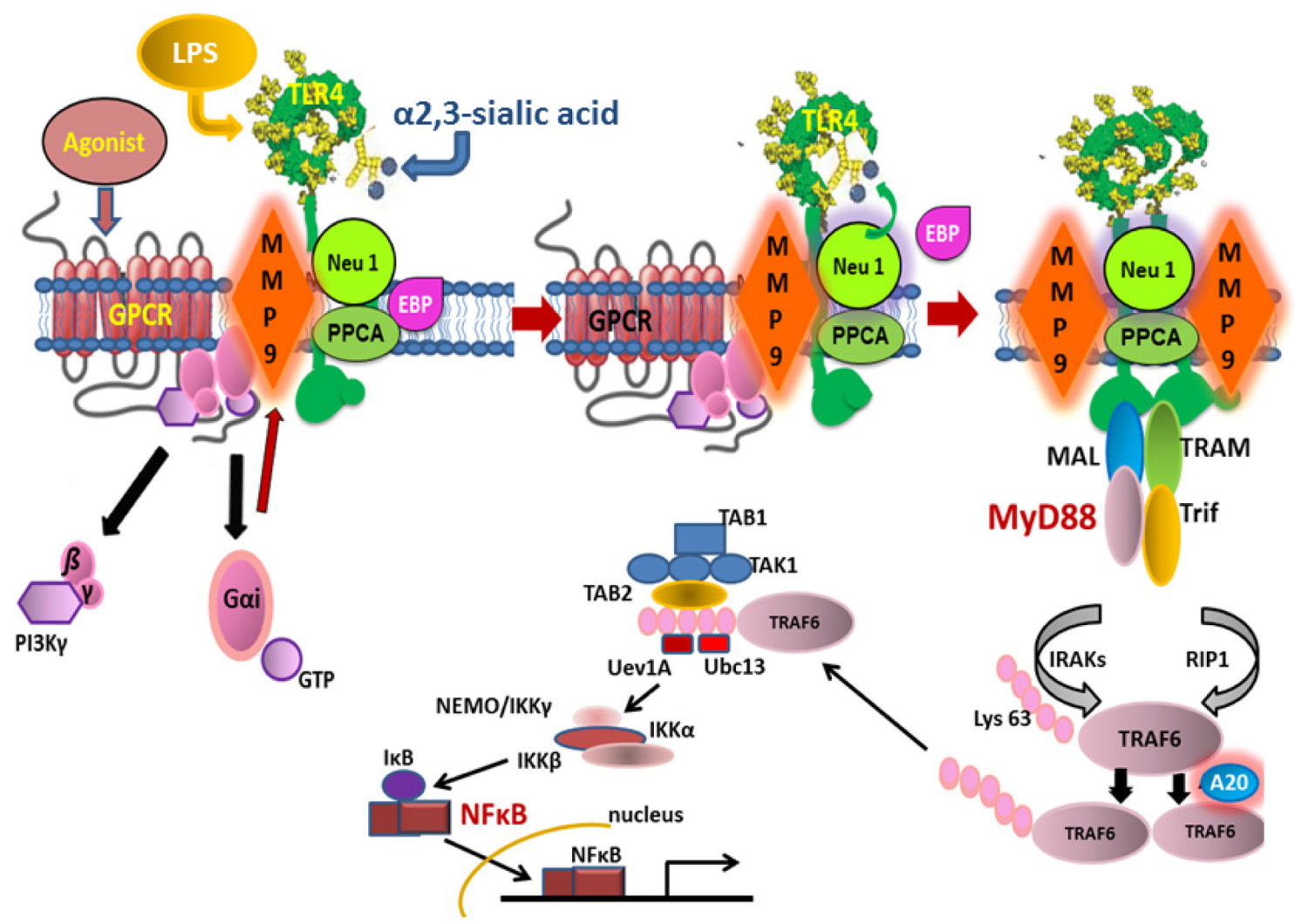

Figure 3 GPCR agonists activate GPCR tethered to TLR4 and MMP9 to induce Neul sialidase ${ }^{78}$ in macrophage cells.

Notes: Reciprocally, endotoxin lipopolysaccharide (LPS)-binding TLR4 induces GPCR tethered to TLR4 and MMP9. ${ }^{84}$ GPCR agonists or TLR ligands involve the activation of GPCR-signaling via pertussis toxin-sensitive G $\alpha$-proteins to induce MMP-9. Activated MMP-9 is proposed to remove elastin-binding protein (EBP) to activate Neul in complex with protective protein cathepsin A (PPCA). Activated Neul hydrolyzes $\alpha 2,3$-sialic acid residues at the ectodomain of the TLR4 receptor to facilitate receptor association, MyD88 recruitment, and subsequent downstream NF- $\mathrm{KB}$ activation.

Abbreviations: TLR4, Toll-like receptor 4; Neu, neuraminidase; PPCA, protective protein cathepsin A; GTP, guanine triphosphate; EBP, elastin-binding protein; MyD88, myeloid differentiation primary response gene 88; MAL, MyD88-adaptor-like; TRAM, Toll/IL-I receptor (TIR) domain-containing adaptor-inducing interferon- $\beta$ (TRIF)-related adaptor molecule; TRIF, TIR-domain-containing adapter-inducing interferon- $\beta$; IRAK2, interleukin-I receptor-associated kinase-like 2; RIPI, receptor interacting protein I; TRAF6, tumor necrosis factor-receptor associated factor 6; Lys63; lysine 63-linked polyubiquitin chains; A20; ubiquitin-modifying enzyme by removing ubiquitin moieties from the signaling molecule TRAF6; TAKI, transforming growth factor beta (TGF $\beta$ )-activated kinase I; TABI, TGF-beta activated kinase I/mitogen activating protein (MAP) kinase kinase kinase 7 (MAP3K7) binding protein I; Ubcl3, ubiquitin conjugating enzyme I3; Uev IA, an ubiquitin conjugating enzyme variant which is required for Ubcl3

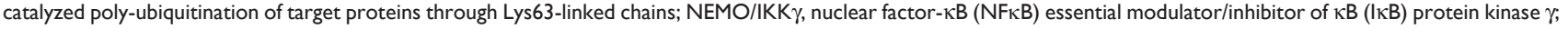
IKK $\gamma$, I B kinase $\gamma$; IKB, nuclear factor of $\kappa$ light polypeptide gene enhancer in B-cell inhibitor; NFKB, nuclear factor $\kappa$ light-chain enhancer of activated $B$ cells. 
with the TLR receptor, as previously proposed by us, ${ }^{84}$ but the subsequent bombesin-induced NF- $\mathrm{KB}$ is actually mediated through the activation of TLR (see Figure 3 ).

\section{Novel GPCR-signaling platform and its targeted translation to human disease}

GPCRs have long been implicated in the transactivation of receptor tyrosine kinases (RTKs) in the absence of added growth factor, particularly for the receptors that bind epidermal growth factor, platelet-derived growth factor, fibroblast growth factor, and neurotrophins such as nerve growth factor. ${ }^{98}$ In a review by Delcourt and colleagues, ${ }^{4}$ the authors provide an eloquent attempt to explain the molecular mechanisms involved in this novel cross-communication between GPCRs and RTKs. Reciprocally, growth factors binding to RTKs also utilize GPCR-signaling molecules to initiate the molecular organizational-signaling platform of a novel Neu1 and MMP-9 cross talk in alliance with RTK on the cell surface. This novel GPCR-signaling platform was identified to be critically essential for neurotrophin NGF-induced receptor tyrosine kinase TrkA and TrkB activation and cellular signaling ${ }^{36}$ (see Figure 1). These findings have revealed a novel concept in which GPCR activation is critically essential for growth-factor activation of RTK by way of a mechanism that involves the formation of a functional signaling complex between the GPCR and RTK. The exact same signaling platform is utilized by Toll-like sensor receptors binding pathogen-associated molecular patterns to activate TLR cellular responses ${ }^{84}$ (Figures 2 and 3). The mechanism(s) of TLR transactivation by GPCR agonists has not been defined until now $^{78}$ (see Figure 3). However, GPCR transactivation by RTK ligands or by TLR pathogen-associated molecular patterns has been established for a few GPCR-RTK ${ }^{4}$ (see Table 1) or GPCR-TLR ${ }^{78}$ pairs. Indeed, there is a need to investigate other partners.
In the context of GPCR-RTK pairs, whether the GPCRs known to promote proliferation signals such as thrombin, angiotensin 2, and endothelin receptors can be transactivated by RTK ligands, or reciprocally RTK transactivation by GPCR agonists remains to be determined. The receptorsignaling paradigm in Figure 1 predicts that RTK receptors are in alliance with a functional GPCR-signaling complex. The data in this and our other reports ${ }^{34-36,84}$ show that ligand binding to respective receptors induces Neu1 sialidase activity within a minute, and that this activity is completely blocked by $G \alpha_{i}$-sensitive pertussis toxin. The rapidity of the ligand-induced Neu1 sialidase activity mediated by the ligand-bound receptor suggests that glycosylated receptors like NGF TrkA, BDNF TrkB, and TLRs ${ }^{34-36,84}$ form a functional signaling complex with $\mathrm{G}_{\mathrm{i}}$ proteins of GPCRs. In support of this hypothesis, GPCR agonists bombesin, LPA, cholesterol, angiotensin-1 and -2 , but not thrombin, induce sialidase activity within a minute, and this activity was blocked by $\mathrm{G}_{\mathrm{i}}$-sensitive pertussis toxin and MMP inhibitors galardin and piperazine. ${ }^{78}$ It is noteworthy that the GPCR agonists can induce sialidase activity in the live-cell assay but the GPCR-mediated effects were not observed in RTK-deficient cells such as NIH-3T3 cells (data unreported). These results suggest that GPCR agonists activate sialidase activity only when Neul and a functional GPCR are tethered to an RTK receptor. To confirm this hypothesis, we recently reported that the GPCR ligand bombesin induced Neu1 activity within a minute and subsequently activated $\mathrm{NF}-\kappa \mathrm{B}$ in macrophage cells. ${ }^{78}$ We also questioned whether the bombesin-like receptor neuromedin B (NMBR) forms a complex with TLR4. Coimmunoprecipitation experiments using cell lysates from BMA macrophage cells showed that NMBR is tethered to TLR4 receptors in naïve and LPS-treated cells. The data validated the predicted alliance between TLR4 and NMBR in naïve macrophage cells. In another report, we have shown that MMP-9 is also tethered

Table I Transactivation of GPCRs by RTK ligands: molecular mechanisms and functions

\begin{tabular}{lllll}
\hline RTK ligand & Transactivated GPCR & Molecular mechanism & Functions & Reference(s) \\
\hline IGF-I & CXCR4 & Physical interaction & Cell migration & 99 \\
IGF-I & CCR5 & Ligand synthesis & Cell migration & 100 \\
IGF-I & PAC, & Physical interaction and phosphorylation & Protection against apoptosis & 101 \\
IGF-I & SIP, & Cell migration & 102 \\
Insulin & $\beta 2$ adrenoceptor & Phosphorylation & Unknown & 103 \\
PDGF & SIP & Ligand synthesis and physical interaction & Cell motility and migration & $104-I I I$ \\
NGF & SIP & Ligand synthesis & Neurite outgrowth & II2 \\
NGF & LPA & Physical interaction & Neurite outgrowth & II3,II4 \\
\hline
\end{tabular}

Note: Reprinted from Trends in Pharmacological Sciences, 28(I2), Review A Novel GPCR receptor signalling platform and its targeted translation in human disease, Delcourt N, Bockaert J, Marin P, 602-607. Copyright 2007, with permission from Elsevier. ${ }^{4}$

Abbreviations: RTK, receptor tyrosine kinase; GPCR, G-protein-coupled receptor; IGF-I, insulin-like growth factor I; CXCR4, CXC chemokine receptor type 4; CCR5, CC chemokine receptor 5; PAC, neuropeptide GPCR PACI; SIP , sphingosine I-phosphate receptor I; PDGF, platelet-derived growth factor; NGF, nerve growth factor;

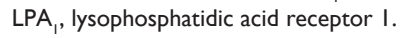


to TLR4 receptors in both naive and LPS-treated BMA cells. ${ }^{84}$ Conversely, TLR4 was found to be coimmunoprecipitated with MMP-9. Since both MMP-9 and NMBR form a complex with TLR4 receptors, we asked whether or not they are associated with each other. Coimmunoprecipitation experiments using cell lysates from RAW-Blue cells further demonstrated that NMBR $80 \mathrm{kDa}$ isoform forms a complex with the active $88 \mathrm{kDa}$ MMP9 isoform from naïve or LPS-stimulated cells. ${ }^{78}$ These data further validated that NMBR forms a complex with MMP-9 on the cell surface of naïve cells. The data in this report also showed that GPCR agonists such as bombesin, LPA, cholesterol, angiotensin-1 and -2 , and bradykinin binding to their respective GPCR receptors induced Neul activity within 1 minute and that this activity was blocked by $\mathrm{G} \alpha_{\mathrm{i}}$-sensitive pertussis toxin, neuraminidase inhibitor Tamiflu, broad-range MMP inhibitors galardin and piperazine, anti-Neu1 and anti-MMP-9 antibodies, and siRNA knockdown of MMP-9. The rapidity of the GPCR agonist-induced Neul activity suggests that glycosylated receptors like TLRs as well as RTK receptors form a functional GPCR-signaling complex.

Other reports have provided compelling evidence to show that the glycosylated platelet-derived growth factor- $\beta$ receptor is tethered to an endogenous GPCR(s) and to a recombinant endothelial differentiation gene-1 protein (EDG1) in HEK-293 cells. ${ }^{107}$ EDG1 is also known as the $\mathrm{S} 1 \mathrm{P}$ receptor $1\left(\mathrm{~S}_{\mathrm{PR}}\right)$ which is encoded by the S1PRI gene. SIPR 1 encodes a GPCR that binds the lipid-signaling molecule sphingosine 1-phosphate (S1P). S1P and LPA are both bioactive lipid phosphates. Moughal et al reported that the constitutively active LPA GPCR receptor enables $_{1}$ G $\beta \gamma$ subunit proteins for use by the TrkA receptor. ${ }^{114}$ These G $\beta \gamma$ subunits were found to enhance the ability of NGF to promote TrkA signaling and subsequently regulate $\mathrm{p} 42 / \mathrm{p} 44$ MAPK signaling pathway in PC12 rat pheochromocytoma cell line. ${ }^{113}$ LPA1 GPCR was found to coimmunoprecipitate with naïve and NGF-treated TrkA receptors in cell lysates, suggesting that LPA 1 GPCR forms a complex with TrkA. ${ }^{114}$ In addition, the findings suggest that NGF-induced stimulation of $\mathrm{p} 42 / \mathrm{p} 44$ MAPK through the TrkA-LPA 1 receptor complex appears to be dependent on G $\beta \gamma$ subunit proteins, while the activation of the $\mathrm{p} 42 / \mathrm{p} 44$ MAPK cascade in response to LPA may involve predominantly $\mathrm{G}_{\mathrm{i} 2}$ subunit proteins. However, the LPA-induced stimulation of $\mathrm{p} 42 /$ p44MAPK was also found to be independent of the TrkA receptor in these studies. ${ }^{113}$

Although GPCRs can exist as monomers, they can also form oligomeric structures composed of either homo- or heteromers, which may play important roles in modulating
Table 2 Review articles on G-protein-coupled receptor function in human diseases

\begin{tabular}{|c|c|c|}
\hline $\begin{array}{l}\text { Disease } \\
\text { category }\end{array}$ & $\begin{array}{l}\text { Specific } \\
\text { pathologies }\end{array}$ & References \\
\hline Cancer & $\begin{array}{l}\text { Breast cancer } \\
\text { Bronchial cancer } \\
\text { Colon cancer } \\
\text { Intestinal cancer } \\
\text { Kaposi's sarcoma } \\
\text { Neuroadrenal cancer } \\
\text { Pancreatic cancer } \\
\text { Pituitary cancer } \\
\text { Prostate cancer } \\
\text { Small-cell lung cancer } \\
\text { Thyroid cancer }\end{array}$ & $4,124-132$ \\
\hline Cardiovascular & $\begin{array}{l}\text { Heart disease } \\
\text { Heart failure } \\
\text { Hypertension }\end{array}$ & $126,128,133$ \\
\hline Developmental & $\begin{array}{l}\text { Precocious puberty } \\
\text { Jansen's metaphyseal } \\
\text { chondrodysplasia }\end{array}$ & $\begin{array}{l}4,124,125 \\
128,129\end{array}$ \\
\hline Inflammatry & $\begin{array}{l}\text { Multiple sclerosis } \\
\text { Macrophage }\end{array}$ & 134 \\
\hline Metabolic & $\begin{array}{l}\text { Obesity } \\
\text { Type } 2 \text { diabetes } \\
\text { Nephrogenic diabetes insipidus } \\
\text { Cushing's disease }\end{array}$ & $\begin{array}{l}\mid 25,127 \\
|28,| 35-137\end{array}$ \\
\hline Neurological & $\begin{array}{l}\text { Alzheimer's disease } \\
\text { Developmental delay }\end{array}$ & $\begin{array}{l}4,125,126 \\
128,138\end{array}$ \\
\hline Reproductive & $\begin{array}{l}\text { Ovarian hyperstimulation } \\
\text { syndrome } \\
\text { Fertility complications }\end{array}$ & 128 \\
\hline Vision & $\begin{array}{l}\text { Retinitis pigmentitis } \\
\text { Stationary night blindness }\end{array}$ & $\begin{array}{l}124,125,128 \\
136,137\end{array}$ \\
\hline
\end{tabular}

and fine-tuning GPCR function ${ }^{115}$ and GPCR-signaling specificity. ${ }^{2,93}$ There are several examples in the literature that show the importance of heteromerization in receptor functions. They suggest that alterations in GPCR cross talk can directly impact health and disease (Table 2). It follows that selective drugs targeting heteromers are of interest for pharmaceutical companies, and thus they constitute proof of heteromer existence in vivo. There are several review articles in the literature that focus on drug design targeting heteromers of GPCR, and they include (1) tools for drug discovery, ${ }^{116}(2)$ the structure of secreting family of GPCR peptide ligands, ${ }^{117}$ (3) drug-induced inactivation and reactivation to reveal GPCR dimer functions, ${ }^{118}$ (4) calcitoningene-related peptide-receptor antagonists and migraine, ${ }^{119}$ (5) pepducins (cell-penetrating lipidated peptides designed to target the intracellular loops of GPCR in disease models, ${ }^{120}$ ) (6) GPCR expression in tissues and cells for optimal drug targeting, ${ }^{121}$ (7) use of GPCR structures for drug design, ${ }^{122}$ (8) drug design of GPCR ligands using physicogenetics and chemogenomics, ${ }^{123}$ and (9) orphan GPCRs modulating the 
function of well-defined drug targets such as GPCRs with identified ligands and neurotransmitter transporters through physical association with those molecules. ${ }^{10}$

In the context of GPCR oligomers when designing new drugs or alternative therapies against human disease, dysregulation of GPCR function is also associated with a growing number of human diseases. ${ }^{124}$ There are two mutational forms of GPCRs; the receptor loses the ability to bind agonist or signal ("loss of function" mutation) or the receptor is in an active state in the absence of agonist ("gain of function" mutation). ${ }^{125}$ A review article by Spiegel and Weinstein ${ }^{125}$ eloquently describes the mutations in the gene encoding the $\alpha$ subunit of the GPCRs. For example, there are mutations of the $\alpha$ subunit involved in the stimulation of adenylyl cyclase causing the developmental abnormalities of bone, as well as hormone resistance (pseudohypoparathyroidism caused by loss-of-function mutations) and hormone hypersecretion (McCune-Albright syndrome caused by gain-of-function mutations). Loss- and gain-of-function mutations in genes encoding GPCRs have been identified as the cause of an increasing number of retinal, endocrine, metabolic, and developmental disorders. ${ }^{125}$

There are a number of constitutively active GPCRs, especially those that are tumorigenic in vitro and in animal models of human disease, that cause syndromes of hyperfunction and/or tumors in humans. ${ }^{124}$ A review article by Arvanitakis et al describes the spectrum of diseases caused by constitutively active GPCRs, including diseases involving infectious viral agents. ${ }^{124}$ To identify the GPCRs involved in human diseases, the review article by Schöneberg et al extensively describes the mutant GPCRs as a cause of human diseases. ${ }^{128}$ To date, over 600 inactivating and almost 100 activating mutations in GPCR have been identified, which are responsible for more than 30 different human diseases. The number of human disorders is expected to increase, given the fact that over 160 GPCRs have been targeted in mice. ${ }^{128}$

In addition to the diseases caused by loss-of-function mutations in GPCRs, dysfunction in basal activity can also cause human diseases. ${ }^{139}$ A review article by Tao ${ }^{139}$ summarizes several diseased states caused by either constitutive activation (eg, rhodopsin mutations and retinitis pigmentosa or congenital stationary night blindness, TSH receptor mutations and hyperthyroidism, luteinizing hormone/choriogonadotropin receptor mutations and male-limited precocious puberty/Leydig cell adenoma, FSH receptor mutations and spontaneous ovarian hyperstimulation syndrome, parathyroid hormone receptor type 1 mutations, and Jansen's metaphyseal chondrodysplasia) or loss of constitutive activity (eg, melanocortin-4 receptor mutations and obesity, growth hormone secretagogue receptor mutations and familial short stature/obesity). The evidence that the loss of constitutive activity in the mutant GPCR receptors can cause disease signifies the critical importance of the basal activity in the WT GPCRs in normal physiology. ${ }^{139}$

In conclusion, the identification of diseases caused by mutations in GPCRs should provide advances in novel forms of treatment for such diseases, including development of inverse agonists ${ }^{118}$ or pepducins ${ }^{120}$ to inhibit constitutively activated GPCRs, and methods to rescue function of misfolded or truncated GPCRs. ${ }^{107,136,137}$ These mutations may define critical GPCR structure-function relationships. Indeed, gene knockouts of GPCR in mice reveal many nonredundant, functionally important $\mathrm{G}$ proteins and GPCRs for which no human disease-causing mutations have yet been identified. ${ }^{125}$ Moreover, there are multiple orphan GPCRs for which the natural agonist is widely unknown. Given the large number of human GPCRs, estimated to be more than 800 , additional examples of the pathogenic mechanisms and drug therapies are likely to be discovered in the future. In this respect, the future research focus might be directed at macrophage-mediated inflammation, as reviewed by Talukdar et al. ${ }^{135}$ Indeed, macrophage-mediated inflammation has been associated with many human diseases. They include rheumatoid arthritis, cancer, inflammatory bowel disease, cardiovascular disease, psoriasis, multiple sclerosis, and periodontitis. Furthermore, the expression of GPCRs differs in proinflammatory and anti-inflammatory macrophages. ${ }^{134}$ According to the novel GPCR-signaling platform (Figures 1 and 3) that is utilized by RTK and TLR receptors for downstream signaling and cellular function, we propose that there is a common GPCR tethered to these receptors. ${ }^{78}$ The findings propose a novel GPCR-signaling platform at the receptor level that has a common uncharacterized property with broader specificities than expected. Since several macrophage-expressed GPCRs have been identified and targeted with therapeutic intent in human diseases which involve infectious disease to cancer, studies about the key players involved in the GPCR agonist-induced transactivation of TLR receptors in the absence of TLR ligands, or reciprocally, TLR ligands potentiating GPCRsignaling to activate MMP-9 and Neu1 would radically redefine the current dogma(s) governing the mechanism of the cross talk between GPCR and TLR activation and cellular signaling. Targeting the molecular GPCR-signaling platform tethered to RTK or TLR receptors may provide 
important pioneering approaches to disease-intervention strategies.

\section{Acknowledgment}

These studies were supported by a grant to MRS from the Natural Sciences and Engineering Research Council of Canada (NSERC). SA was the recipient of the RS McLaughlin Scholarship, the Ontario Graduate Scholarship, and now the Canadian Institutes of Health Research (CIHR) Doctoral Award: Frederick Banting and Charles Best Canada Graduate Scholarship. MH is the recipient of the NSERC Canada Graduate Scholarship (CGS-D3).

\section{Disclosure}

The authors report no conflicts of interest in this work.

\section{References}

1. Marinissen MJ, Gutkind JS. G-protein-coupled receptors and signaling networks: emerging paradigms. Trends Pharmacol Sci. 2001;22(7): 368-376.

2. Rozenfeld R, Devi LA. Exploring a role for heteromerization in GPCR signalling specificity. Biochem J. 2011;433(1):11-18

3. Penela P, Lafarga V, Tapia O, et al. Roles of GRK2 in cell signaling beyond GPCR desensitization: GRK2-HDAC6 interaction modulates cell spreading and motility. Sci Signal. 2012;5(224):pt3.

4. Delcourt N, Bockaert J, Marin P. GPCR-jacking: from a new route in RTK signalling to a new concept in GPCR activation. Trends Pharmacol Sci. 2007;28(12):602-607.

5. Halls ML. Constitutive formation of an RXFP1-signalosome: a novel paradigm in GPCR function and regulation. Br J Pharmacol. 2012;165(6):1644-1658.

6. Gurevich VV, Gurevich EV. Rich tapestry of G protein-coupled receptor signaling and regulatory mechanisms. Mol Pharmacol. 2008;74(2): 312-316.

7. Magalhaes AC, Dunn H, Ferguson SS. Regulation of GPCR activity, trafficking and localization by GPCR-interacting proteins. $\mathrm{Br} J$ Pharmacol. 2012;165(6):1717-1736.

8. Wu J, Xie N, Zhao X, Nice EC, Huang C. Dissection of aberrant GPCR signaling in tumorigenesis - a systems biology approach. Cancer Genomics Proteomics. 2012;9(1):37-50

9. Hollmann MW, Strumper D, Herroeder S, Durieux ME. Receptors, G proteins, and their interactions. Anesthesiology. 2005;103(5):1066-1078

10. Levoye A, Jockers R. Alternative drug discovery approaches for orphan GPCRs. Drug Discov Today. 2008;13(1-2):52-58.

11. Ronnett GV, Knutson VP, Kohanski RA, Simpson TL, Lane MD. Role of glycosylation in the processing of newly translated insulin proreceptor in 3T3-L1 adipocytes. J Biol Chem. 1984;259(7):4566-4575.

12. Soderquist AM, Carpenter G. Glycosylation of the epidermal growth factor receptor in A-431 cells. The contribution of carbohydrate to receptor function. J Biol Chem. 1984;259(20):12586-12594.

13. Slieker LJ, Lane MD. Post-translational processing of the epidermal growth factor receptor. Glycosylation-dependent acquisition of ligandbinding capacity. J Biol Chem. 1985;260(2):687-690.

14. Merlie JP, Smith MM. Synthesis and assembly of acetylcholine receptor, a multisubunit membrane glycoprotein. J Membr Biol. 1986;91(1): 1-10.

15. Rens-Domiano S, Reisine T. Structural analysis and functional role of the carbohydrate component of somatostatin receptors. J Biol Chem. 1991;266(30):20094-20102.

16. Rands E, Candelore MR, Cheung AH, Hill WS, Strader CD, Dixon RA. Mutational analysis of beta-adrenergic receptor glycosylation. J Biol Chem. 1990;265(18):10759-10764.
17. Cervantes-Olivier P, Delavier-Klutchko C, Durieu-Trautmann O, Kaveri S, Desmandril M, Strosberg AD. The beta 2-adrenergic receptors of human epidermoid carcinoma cells bear two different types of oligosaccharides which influence expression on the cell surface. Biochem J. 1988;250(1):133-143.

18. Watson FL, Porcionatto MA, Bhattacharyya A, Stiles CD, Segal RA. TrkA glycosylation regulates receptor localization and activity. J Neurobiol. 1999;39(2):323-336.

19. Woronowicz A, De Vusser K, Laroy W, et al. Trypanosome transsialidase targets TrkA tyrosine kinase receptor and induces receptor internalization and activation. Glycobiology. 2004;14(11):987-998.

20. Woronowicz A, Amith SR, Davis VW, et al. Trypanosome trans-sialidase mediates neuroprotection against oxidative stress, serum/glucose deprivation, and hypoxia-induced neurite retraction in Trk-expressing PC12 cells. Glycobiology. 2007;17(7):725-734.

21. Woronowicz A, Amith SR, De Vusser K, et al. Dependence of neurotrophic factor activation of Trk tyrosine kinase receptors on cellular sialidase. Glycobiology. 2007;17(1):10-24.

22. Keppler OT, Hinderlich S, Langner J, Schwartz-Albiez R, Reutter W, Pawlita M. UDP-GlcNAc 2-epimerase: a regulator of cell surface sialylation. Science. 1999;284(5418):1372-1376.

23. Baker MA, Kanani A, Brockhausen I, Schachter H, Hindenburg A, Taub RN. Presence of cytidine 5'-monophospho-N-acetylneuraminic acid:Gal beta 1-3GalNAc-R alpha(2-3)-sialyltransferase in normal human leukocytes and increased activity of this enzyme in granulocytes from chronic myelogenous leukemia patients. Cancer Res. 1987;47(11): 2763-2766.

24. Dalziel M, Whitehouse C, McFarlane I, et al. The relative activities of the C2GnT1 and ST3Gal-I glycosyltransferases determine O-glycan structure and expression of a tumor-associated epitope on MUC1. J Biol Chem. 2001;276(14):11007-11015.

25. Abo S, Ciccotosto S, Alafaci A, von Itzstein M. The synthesis and evaluation of novel sialic acid analogues bound to matrices for the purification of sialic acid-recognising proteins. Carbohydr Res. 1999;322(3-4): 201-208.

26. Crocker PR, Mucklow S, Bouckson V, et al. Sialoadhesin, a macrophage sialic acid binding receptor for haemopoietic cells with 17 immunoglobulin-like domains. EMBO J. 1994;13(19):4490-4503.

27. Doherty P, Fazeli MS, Walsh FS. The neural cell adhesion molecule and synaptic plasticity. J Neurobiol. 1995;26(3):437-446.

28. Munday J, Floyd H, Crocker PR. Sialic acid binding receptors (siglecs) expressed by macrophages. J Leukoc Biol. 1999;66(5):705-711.

29. Takano R, Muchmore E, Dennis JW. Sialylation and malignant potential in tumor-cell glycosylation mutants. Glycobiology. 1994;4(5):665-674

30. Schauer R. Achievements and challenges of sialic acid research. Glycoconj J. 2000;17(7-9):485-499.

31. Schauer R, de Freese A, Gollub M, et al. Functional and biosynthetic aspects of sialic acid diversity. Indian J Biochem Biophys. 1997;34(1-2): 131-141.

32. Schauer R. Chemistry, metabolism, and biological functions of sialic acids. Adv Carbohydr Chem Biochem. 1982;40:131-234.

33. Moloney DJ, Panin VM, Johnson SH, et al. Modulation of signal transduction by differential receptor glycosylation: the role of O-linked fucose in notch signaling. Glycobiology. 2000;10(10):1081-1082.

34. Amith SR, Jayanth P, Franchuk S, et al. Neul desialylation of sialyl alpha-2,3-linked beta-galactosyl residues of TOLL-like receptor 4 is essential for receptor activation and cellular signaling. Cell Signal. 2010;22(2):314-324.

35. Amith SR, Jayanth P, Franchuk S, et al. Dependence of pathogen molecule-induced toll-like receptor activation and cell function on Neu1 sialidase. Glycoconj J. 2009;26(9):1197-1212.

36. Jayanth P, Amith SR, Gee K, Szewczuk MR. Neu1 sialidase and matrix metalloproteinase- 9 cross-talk is essential for neurotrophin activation of Trk receptors and cellular signaling. Cell Signal. 2010;22(8) 1193-1205.

37. Murphy G, Nagase H. Progress in matrix metalloproteinase research. Mol Aspects Med. 2008;29(5):290-308. 
38. Zucker S, Moll UM, Lysik RM, DiMassimo EI, Schwedes JW, Liotta LA. Extraction of type IV collagenase/gelatinase from plasma membranes of human pancreatic cancer cells. Matrix Suppl. 1992;1:411.

39. Zucker S, Moll UM, Lysik RM, et al. Extraction of type-IV collagenase/ gelatinase from plasma membranes of human cancer cells. Int J Cancer. 1990;45(6):1137-1142.

40. Senior RM, Connolly NL, Cury JD, Welgus HG, Campbell EJ. Elastin degradation by human alveolar macrophages. A prominent role of metalloproteinase activity. Am Rev Respir Dis. 1989;139(5):1251-1256.

41. Ratzinger G, Stoitzner P, Ebner S, et al. Matrix metalloproteinases 9 and 2 are necessary for the migration of Langerhans cells and dermal dendritic cells from human and murine skin. J Immunol. 2002;168(9): 4361-4371.

42. Liang F, Seyrantepe V, Landry K, et al. Monocyte differentiation up-regulates the expression of the lysosomal sialidase, Neu1, and triggers its targeting to the plasma membrane via major histocompatibility complex class II-positive compartments. J Biol Chem. 2006;281(37):27526-27538.

43. van der Spoel A, Bonten E, d'Azzo A. Transport of human lysosomal neuraminidase to mature lysosomes requires protective protein/ cathepsin A. EMBO J. 1998;17(6):1588-1597.

44. Hinek A, Pshezhetsky AV, Von IM, Starcher B. Lysosomal sialidase (neuraminidase-1) is targeted to the cell surface in a multiprotein complex that facilitates elastic fiber assembly. J Biol Chem. 2006;281(6): 3698-3710.

45. Duca L, Blanchevoye C, Cantarelli B, et al. The elastin receptor complex transduces signals through the catalytic activity of its Neu-1 subunit. J Biol Chem. 2007;282(17):12484-12491.

46. Lukong KE, Seyrantepe V, Landry K, et al. Intracellular distribution of lysosomal sialidase is controlled by the internalization signal in its cytoplasmic tail. J Biol Chem. 2001;276(49):46172-46181.

47. Yogalingam G, Bonten EJ, van de Vlekkert D, et al. Neuraminidase 1 is a negative regulator of lysosomal exocytosis. Dev Cell. 2008;15(1): $74-86$.

48. Miyagi T, Sagawa J, Konno K, Tsuiki S. Immunological discrimination of intralysosomal, cytosolic, and two membrane sialidases present in rat tissues. J Biochem. 1990;107(5):794-798.

49. Sato K, Miyagi T. Involvement of an endogenous sialidase in skeletal muscle cell differentiation. Biochem Biophys Res Commun. 1996; 221(3):826-830

50. Fanzani A, Giuliani R, Colombo F, et al. Overexpression of cytosolic sialidase Neu2 induces myoblast differentiation in $\mathrm{C} 2 \mathrm{C} 12$ cells. FEBS Lett. 2003;547(1-3):183-188.

51. Miyagi T, Tsuiki S. Purification and characterization of cytosolic sialidase from rat liver. J Biol Chem. 1985;260(11):6710-6716.

52. Kotani K, Kuroiwa A, Saito T, Matsuda Y, Koda T, Kijimoto-Ochiai S. Cloning, chromosomal mapping, and characteristic $5^{\prime}$-UTR sequence of murine cytosolic sialidase. Biochem Biophys Res Commun. 2001;286(2):250-258.

53. Hasegawa T, Feijoo CC, Wada T, Itoyama Y, Miyagi T. Differential expression of three sialidase genes in rat development. Biochem Biophys Res Commun. 2001;280(3):726-732.

54. Rodriguez JA, Piddini E, Hasegawa T, Miyagi T, Dotti CG. Plasma membrane ganglioside sialidase regulates axonal growth and regeneration in hippocampal neurons in culture. $J$ Neurosci. 2001;21(21): 8387-8395.

55. Sasaki A, Hata K, Suzuki S, et al. Overexpression of plasma membraneassociated sialidase attenuates insulin signaling in transgenic mice. J Biol Chem. 2003;278(30):27896-27902.

56. Papini N, Anastasia L, Tringali C, et al. The plasma membraneassociated sialidase MmNEU3 modifies the ganglioside pattern of adjacent cells supporting its involvement in cell-to-cell interactions. J Biol Chem. 2004;279(17):16989-16995.

57. Kopitz J, von RC, Burchert M, Cantz M, Gabius HJ. Galectin-1 is a major receptor for ganglioside GM1, a product of the growth-controlling activity of a cell surface ganglioside sialidase, on human neuroblastoma cells in culture. J Biol Chem. 1998;273(18):11205-11211.
58. Miyagi T, Tsuiki S. Evidence for sialidase hydrolyzing gangliosides GM2 and GM1 in rat liver plasma membrane. FEBS Lett. 1986;206(2): 223-228.

59. Comelli EM, Amado M, Lustig SR, Paulson JC. Identification and expression of Neu4, a novel murine sialidase. Gene. 2003;321:155-161.

60. Yamaguchi K, Hata K, Koseki K, et al. Evidence for mitochondrial localization of a novel human sialidase (NEU4). Biochem J. 2005; 390(Pt 1):85-93.

61. Seyrantepe V, Landry K, Trudel S, Hassan JA, Morales CR, Pshezhetsky AV. Neu4, a novel human lysosomal lumen sialidase, confers normal phenotype to sialidosis and galactosialidosis cells. J Biol Chem. 2004;279(35):37021-37029.

62. Finlay TM, Abdulkhalek S, Gilmour A, et al. Thymoquinone-induced Neu4 sialidase activates NFkappaB in macrophage cells and proinflammatory cytokines in vivo. Glycoconj J. 2010;27(6):583-600.

63. Finlay TM, Jayanth P, Amith SR, et al. Thymoquinone from nutraceutical black cumin oil activates Neu4 sialidase in live macrophage, dendritic, and normal and type I sialidosis human fibroblast cells via GPCR Galphai proteins and matrix metalloproteinase-9. Glycoconj J. 2010;27(3):329-348.

64. Nan X, Carubelli I, Stamatos NM. Sialidase expression in activated human T lymphocytes influences production of IFN-gamma. J Leukoc Biol. 2007;81(1):284-296.

65. Chen XP, Enioutina EY, Daynes RA. The control of IL-4 gene expression in activated murine $\mathrm{T}$ lymphocytes: a novel role for neu-1 sialidase. J Immunol. 1997;158(7):3070-3080.

66. Kacergius T, Ambrozaitis A, Deng Y, Gravenstein S. Neuraminidase inhibitors reduce nitric oxide production in influenza virus-infected and gamma interferon-activated RAW 264.7 macrophages. Pharmacol Rep. 2006;58(6):924-930.

67. Mendel DB, Tai CY, Escarpe PA, et al. Oral administration of a prodrug of the influenza virus neuraminidase inhibitor GS 4071 protects mice and ferrets against influenza infection. Antimicrob Agents Chemother. 1998;42(3):640-646.

68. Shi D, Yang J, Yang D, et al. Anti-influenza prodrug oseltamivir is activated by carboxylesterase human carboxylesterase 1 , and the activation is inhibited by antiplatelet agent clopidogrel. $J$ Pharmacol Exp Ther. 2006;319(3):1477-1484.

69. Amith SR, Jayanth P, Finlay T, et al. Detection of Neu1 sialidase activity in regulating Toll-like receptor activation. JVis Exp. 2010(43): pii 2142.

70. Lattin J, Zidar DA, Schroder K, Kellie S, Hume DA, Sweet MJ. G-protein-coupled receptor expression, function, and signaling in macrophages. J Leukoc Biol. 2007;82(1):16-32.

71. Loniewski K, Shi Y, Pestka J, Parameswaran N. Toll-like receptors differentially regulate GPCR kinases and arrestins in primary macrophages. Mol Immunol. 2008;45(8):2312-2322.

72. Wieland T, Mittmann C. Regulators of G-protein signalling: multifunctional proteins with impact on signalling in the cardiovascular system. Pharmacol Ther. 2003;97(2):95-115.

73. Booth RA, Cummings C, Tiberi M, Liu XJ. GIPC participates in G protein signaling downstream of insulin-like growth factor 1 receptor. J Biol Chem. 2002;277(8):6719-6725.

74. Lou X, Yano H, Lee F, Chao MV, Farquhar MG. GIPC and GAIP form a complex with TrkA: a putative link between $\mathrm{G}$ protein and receptor tyrosine kinase pathways. Mol Biol Cell. 2001;12(3):615-627.

75. Rallabhandi P, Nhu QM, Toshchakov VY, et al. Analysis of proteinase-activated receptor 2 and TLR4 signal transduction: a novel paradigm for receptor cooperativity. J Biol Chem. 2008;283(36): 24314-24325.

76. Solomon KR, Kurt-Jones EA, Saladino RA, et al. Heterotrimeric G proteins physically associated with the lipopolysaccharide receptor CD14 modulate both in vivo and in vitro responses to lipopolysaccharide. J Clin Invest. 1998;102(11):2019-2027.

77. Pfeiffer A, Bottcher A, Orso E, et al. Lipopolysaccharide and ceramide docking to $\mathrm{CD} 14$ provokes ligand-specific receptor clustering in rafts. Eur J Immunol. 2001;31(11):3153-3164. 
78. Abdulkhalek S, Guo M, Amith SR, Jayanth P, Szewczuk MR. G-protein coupled receptor agonists mediate Neul sialidase and matrix metalloproteinase- 9 cross-talk to induce transactivation of TOLL-like receptors and cellular signaling. Cell Signal. 2012;24(11):2035-2042.

79. Shi GX, Harrison K, Han SB, Moratz C, Kehrl JH. Toll-like receptor signaling alters the expression of regulator of $\mathrm{G}$ protein signaling proteins in dendritic cells: implications for $\mathrm{G}$ protein-coupled receptor signaling. J Immunol. 2004;172(9):5175-5184.

80. Ferlito M, Romanenko OG, Guyton K, et al. Implication of Galpha i proteins and Src tyrosine kinases in endotoxin-induced signal transduction events and mediator production. J Endotoxin Res. 2002; 8(6):427-435.

81. Fan H, Zingarelli B, Peck OM, et al. Lipopolysaccharide- and grampositive bacteria-induced cellular inflammatory responses: role of heterotrimeric Galpha(i) proteins. Am J Physiol Cell Physiol. 2005;289(2):C293-C301.

82. Lentschat A, Karahashi H, Michelsen KS, et al. Mastoparan, a G protein agonist peptide, differentially modulates TLR4- and TLR2mediated signaling in human endothelial cells and murine macrophages. J Immunol. 2005;174(7):4252-4261.

83. Sugama J, Ohkubo S, Atsumi M, Nakahata N. Mastoparan changes the cellular localization of Galphaq/11 and Gbeta through its binding to ganglioside in lipid rafts. Mol Pharmacol. 2005;68(5): 1466-1474.

84. Abdulkhalek S, Amith SR, Franchuk SL, et al. Neul sialidase and matrix metalloproteinase-9 cross-talk is essential for Toll-like receptor activation and cellular signaling. J Biol Chem. 2011;286(42): 36532-36549.

85. Fischer OM, Hart S, Ullrich A. Dissecting the epidermal growth factor receptor signal transactivation pathway. Methods Mol Biol. 2006; 327:85-97.

86. Lee MH, Murphy G. Matrix metalloproteinases at a glance. J Cell Sci. 2004;117(18):4015-4016.

87. Le Gall SM, Auger R, Dreux C, Mauduit P. Regulated cell surface proEGF ectodomain shedding is a zinc metalloprotease-dependent process. J Biol Chem. 2003;278(46):45255-45268.

88. Murasawa S, Mori Y, Nozawa Y, et al. Angiotensin II type 1 receptorinduced extracellular signal-regulated protein kinase activation is mediated by $\mathrm{Ca} 2+/$ calmodulin-dependent transactivation of epidermal growth factor receptor. Circ Res. 1998;82(12):1338-1348.

89. Gooz M, Gooz P, Luttrell LM, Raymond JR. 5-HT2A receptor induces ERK phosphorylation and proliferation through ADAM-17 tumor necrosis factor- $\{$ alpha $\}$-converting enzyme (TACE) activation and heparinbound epidermal growth factor-like growth factor (HB-EGF) shedding in mesangial cells. J Biol Chem. 2006;281(30): 21004-21012.

90. Prenzel N, Zwick E, Daub H, et al. EGF receptor transactivation by G-protein-coupled receptors requires metalloproteinase cleavage of proHB-EGF. Nature. 1999;402(6764):884-888.

91. Paila YD, Chattopadhyay A. Membrane cholesterol in the function and organization of G-protein coupled receptors. Subcell Biochem. 2010;51:439-466.

92. Alexander SP, Mathie A, Peters JA. Guide to Receptors and Channels (GRAC), 3rd ed. Br J Pharmacol. 2008;153 Supp1 2:S1-S209.

93. Eskan MA, Rose BG, Benakanakere MR, et al. TLR4 and S1P receptors cooperate to enhance inflammatory cytokine production in human gingival epithelial cells. Eur J Immunol. 2008;38(4):1138-1147.

94. Gouwy M, Struyf S, Verbeke H, et al. CC chemokine ligand-2 synergizes with the nonchemokine G protein-coupled receptor ligand FMLP in monocyte chemotaxis, and it cooperates with the TLR ligand LPS via induction of CXCL8. J Leukoc Biol. 2009;86(3):671-680.

95. Lattin JE, Greenwood KP, Daly NL, et al. Beta-arrestin 2 is required for complement $\mathrm{C} 1 \mathrm{q}$ expression in macrophages and constrains factorindependent survival. Mol Immunol. 2009;47(2-3):340-347.

96. Serezani CH, Lewis C, Jancar S, Peters-Golden M. Leukotriene B4 amplifies NF-kappaB activation in mouse macrophages by reducing SOCS1 inhibition of MyD88 expression. J Clin Invest. 2011;121(2): $671-682$
97. Kim SH, Serezani CH, Okunishi K, Zaslona Z, Aronoff DM, Peters-Golden M. Distinct protein kinase a anchoring proteins direct prostaglandin E2 modulation of toll-like receptor signaling in alveolar macrophages. J Biol Chem. 2011;286(11):8875-8883.

98. Shah BH, Catt KJ. GPCR-mediated transactivation of RTKs in the CNS: mechanisms and consequences. Trends Neurosci. 2004;27(1): 48-53.

99. Akekawatchai C, Holland JD, Kochetkova M, Wallace JC, McColl SR. Transactivation of CXCR4 by the insulin-like growth factor-1 receptor (IGF-1R) in human MDA-MB-231 breast cancer epithelial cells. J Biol Chem. 2005;280(48):39701-39708.

100. Mira E, Lacalle RA, Gonzalez MA, et al. A role for chemokine receptor transactivation in growth factor signaling. EMBO Rep. 2001;2(2): $151-156$

101. Delcourt N, Thouvenot E, Chanrion B, et al. PACAP type I receptor transactivation is essential for IGF-1 receptor signalling and antiapoptotic activity in neurons. EMBO J. 2007;26(6):1542-1551.

102. El-Shewy HM, Johnson KR, Lee MH, Jaffa AA, Obeid LM, Luttrell LM. Insulin-like growth factors mediate heterotrimeric $\mathrm{G}$ protein-dependent ERK1/2 activation by transactivating sphingosine 1-phosphate receptors. J Biol Chem. 2006;281(42): 31399-31407.

103. Valiquette M, Parent S, Loisel TP, Bouvier M. Mutation of tyrosine-141 inhibits insulin-promoted tyrosine phosphorylation and increased responsiveness of the human beta 2-adrenergic receptor. EMBO J. 1995;14(22):5542-5549.

104. Rosenfeldt HM, Hobson JP, Maceyka M, et al. EDG-1 links the PDGF receptor to Src and focal adhesion kinase activation leading to lamellipodia formation and cell migration. FASEB J. 2001;15(14): 2649-2659.

105. Rosenfeldt HM, Hobson JP, Milstien S, Spiegel S. The sphingosine1-phosphate receptor EDG-1 is essential for platelet-derived growth factor-induced cell motility. Biochem Soc Trans. 2001;29(Pt 6): 836-839

106. Hobson JP, Rosenfeldt HM, Barak LS, et al. Role of the sphingosine1-phosphate receptor EDG-1 in PDGF-induced cell motility. Science. 2001;291(5509):1800-1803.

107. Alderton F, Rakhit S, Kong KC, et al. Tethering of the platelet-derived growth factor beta receptor to G-protein-coupled receptors. A novel platform for integrative signaling by these receptor classes in mammalian cells. J Biol Chem. 2001;276(30):28578-28585.

108. Pitson SM, Moretti PA, Zebol JR, et al. Activation of sphingosine kinase 1 by ERK1/2-mediated phosphorylation. EMBO J. 2003;22(20):5491-5500.

109. Waters C, Sambi B, Kong KC, et al. Sphingosine 1-phosphate and platelet-derived growth factor (PDGF) act via PDGF beta receptorsphingosine 1-phosphate receptor complexes in airway smooth muscle cells. J Biol Chem. 2003;278(8):6282-6290.

110. Waters CM, Long J, Gorshkova I, et al. Cell migration activated by platelet-derived growth factor receptor is blocked by an inverse agonist of the sphingosine 1-phosphate receptor-1. FASEB J. 2006;20(3): 509-511.

111. Waters CM, Connell MC, Pyne S, Pyne NJ. c-Src is involved in regulating signal transmission from PDGFbeta receptor-GPCR(s) complexes in mammalian cells. Cell Signal. 2005;17(2):263-277.

112. Toman RE, Payne SG, Watterson KR, et al. Differential transactivation of sphingosine-1-phosphate receptors modulates NGF-induced neurite extension. J Cell Biol. 2004;166(3):381-392.

113. Moughal NA, Waters C, Sambi B, Pyne S, Pyne NJ. Nerve growth factor signaling involves interaction between the Trk A receptor and lysophosphatidate receptor 1 systems: nuclear translocation of the lysophosphatidate receptor 1 and Trk A receptors in pheochromocytoma 12 cells. Cell Signal. 2004;16(1):127-136.

114. Moughal NA, Waters CM, Valentine WJ, et al. Protean agonism of the lysophosphatidic acid receptor-1 with Ki16425 reduces nerve growth factor-induced neurite outgrowth in pheochromocytoma 12 cells. J Neurochem. 2006;98(6):1920-1929. 
115. Tadagaki K, Jockers R, Kamal M. History and biological significance of GPCR heteromerization in the neuroendocrine system. Neuroendocrinology. 2012;95(3):223-231.

116. Zhang R, Xie X. Tools for GPCR drug discovery. Acta Pharmacol Sin. 2012;33(3):372-384.

117. Watkins HA, Au M, Hay DL. The structure of secretin family GPCR peptide ligands: implications for receptor pharmacology and drug development. Drug Discov Today. 2012;17(17-18):1006-1014.

118. Teitler M, Klein MT. A new approach for studying GPCR dimers: drug-induced inactivation and reactivation to reveal GPCR dimer function in vitro, in primary culture, and in vivo. Pharmacol Ther. 2012;133(2):205-217.

119. Moore EL, Salvatore CA. Targeting a family B GPCR/RAMP receptor complex: CGRP receptor antagonists and migraine. Br J Pharmacol. 2012;166(1):66-78.

120. Tressel SL, Koukos G, Tchernychev B, Jacques SL, Covic L, Kuliopulos A. Pharmacology, biodistribution, and efficacy of GPCRbased pepducins in disease models. Methods Mol Biol. 2011;683: 259-275.

121. Insel PA, Snead A, Murray F, et al. GPCR expression in tissues and cells: are the optimal receptors being used as drug targets? Br J Pharmacol. 2012;165(6):1613-1616.

122. Congreve M, Langmead C, Marshall FH. The use of GPCR structures in drug design. Adv Pharmacol. 2011;62:1-36.

123. Frimurer TM, Hogberg T. Drug design of GPCR ligands using physicogenetics and chemogenomics - principles and case studies. Curr Top Med Chem. 2011;11(15):1882-1901.

124. Arvanitakis L, Geras-Raaka E, Gershengorn MC. Constitutively signaling G-protein-coupled receptors and human disease. Trends Endocrinol Metab. 1998;9(1):27-31.

125. Spiegel AM, Weinstein LS. Inherited diseases involving g proteins and g protein-coupled receptors. Annu Review Med. 2004;55:27-39.

126. Alemany R, Perona JS, Sanchez-Dominguez JM, et al. G protein-coupled receptor systems and their lipid environment in health disorders during aging. Biochim Biophys Acta. 2007;1768(4):964-975.

127. Milligan G, Stoddart LA, Brown AJ. G protein-coupled receptors for free fatty acids. Cell Signal. 2006;18(9):1360-1365.
128. Schöneberg T, Schulz A, Biebermann H, Hermsdorf T, Römpler H, Sangkuhl K. Mutant G-protein-coupled receptors as a cause of human diseases. Pharmacol Ther. 2004;104(3):173-206.

129. Reubi JC. Peptide receptors as molecular targets for cancer diagnosis and therapy. Endocr Rev. 2003;24(4):389-427.

130. Fleischmann A, Laderach U, Friess H, Buechler MW, Reubi JC. Bombesin receptors in distinct tissue compartments of human pancreatic diseases. Lab Invest. 2000;80(12):1807-1817.

131. Cornelio DB, Roesler R, Schwartsmann G. Gastrin-releasing peptide receptor as a molecular target in experimental anticancer therapy. Ann Oncol. 2007;18(9):1457-1466.

132. Reubi JC, Wenger S, Schmuckli-Maurer J, Schaer JC, Gugger $\mathrm{M}$. Bombesin receptor subtypes in human cancers: detection with the universal radioligand (125)I-[D-TYR(6), beta-ALA(11), PHE(13), NLE(14)] bombesin(6-14). Clin Cancer Res. 2002;8(4): 1139-1146.

133. Salazar NC, Chen J, Rockman HA. Cardiac GPCRs: GPCR signaling in healthy and failing hearts. Biochim Biophys Acta. 2007;1768(4): 1006-1018.

134. Lattin J, Zidar DA, Schroder K, Kellie S, Hume DA, Sweet MJ. G-protein-coupled receptor expression, function, and signaling in macrophages. J Leukoc Biol. 2007;82(1):16-32.

135. Talukdar S, Olefsky JM, Osborn O. Targeting GPR120 and other fatty acid-sensing GPCRs ameliorates insulin resistance and inflammatory diseases. Trends Pharmacol Sci. 2011;32(9):543-550.

136. Insel PA, Tang CM, Hahntow I, Michel MC. Impact of GPCRs in clinical medicine: monogenic diseases, genetic variants and drug targets. Biochim Biophys Acta. 2007;1768(4):994-1005.

137. Conn PM, Ulloa-Aguirre A, Ito J, Janovick JA. G protein-coupled receptor trafficking in health and disease: lessons learned to prepare for therapeutic mutant rescue in vivo. Pharmacol Rev. 2007;59(3): 225-250.

138. Tsao P, von Zastrow M. Downregulation of $\mathrm{G}$ protein-coupled receptors. Curr Opin Neurobiol. 2000;10(3):365-369.

139. Tao YX. Constitutive activation of $G$ protein-coupled receptors and diseases: insights into mechanisms of activation and therapeutics. Pharmacol Ther. 2008;120(2):129-148.
Research and Reports in Biochemistry

\section{Publish your work in this journal}

Research and Reports in Biochemistry is an international, peer-reviewed, open access journal publishing original research, reports, reviews and commentaries on all areas of biochemistry. The manuscript management system is completely online and includes a very quick and fair

\section{Dovepress}

peer-review system. Visit http://www.dovepress.com/testimonials.php to read real quotes from published authors. 